\title{
Importance of pharmacogenetics in the treatment of children with attention deficit hyperactive disorder: a case report
}

This article was published in the following Dove Press journal:

Pharmacogenomics and Personalized Medicine

10 January 2013

Number of times this article has been viewed

\author{
Teerarat Tan-kam' \\ Chutamanee Suthisisang ${ }^{2}$ \\ Chosita Pavasuthipaisit ${ }^{1}$ \\ Penkhae Limsila' \\ Apichaya Puangpetch ${ }^{3}$ \\ Chonlaphat Sukasem ${ }^{3}$ \\ 'Yuwaprasart Waithayopathum Child \\ and Adolescent Psychiatric Hospital, \\ Department of Mental Health \\ Services, Ministry of Public Health, \\ ${ }^{2}$ Department of Pharmacology, Faculty \\ of Pharmacy, Mahidol University, \\ ${ }^{3}$ Division of Pharmacogenomics and \\ Personalized Medicine, Department \\ of Pathology, Faculty of Medicine, \\ Ramathibodi Hospital, Mahidol \\ University, Bangkok, Thailand
}

\begin{abstract}
This case report highlights the importance of pharmacogenetic testing in the treatment of attention deficit hyperactive disorder (ADHD). A 6-year-old boy diagnosed with ADHD was prescribed methylphenidate $5 \mathrm{mg}$ twice daily ( $7 \mathrm{am}$ and noon) and the family was compliant with administration of this medication. On the first day of treatment, the patient had an adverse reaction, becoming disobedient, more mischievous, erratic, resistant to discipline, would not go to sleep until midnight, and had a poor appetite. The All-In-One PGX (All-In-One Pharmacogenetics for Antipsychotics test for CYP2D6, CYP2C19, and CYP2C9) was performed using microarray-based and real-time polymerase chain reaction techniques. The genotype of our patient was identified to be $C Y P 2 D 6^{*} 2 / * 10$, with isoforms of the enzyme consistent with a predicted cytochrome P450 2D6 intermediate metabolizer phenotype. Consequently, the physician adjusted the methylphenidate dose to $2.5 \mathrm{mg}$ once daily in the morning. At this dosage, the patient had a good response without any further adverse reactions. Pharmacogenetic testing should be included in the management plan for ADHD. In this case, cooperation between the medical team and the patients' relatives was key to successful treatment.
\end{abstract}

Keywords: attention deficit hyperactive disorder, pharmacogenomics, CYP2D6, adverse drug reactions, dose adjustment, intermediate metabolizer

\section{Background}

Attention deficit hyperactivity disorder (ADHD) is a common neurodevelopmental and behavioral disorder, the symptoms of which include inattention, hyperactivity, and/or impulsivity in specific areas. ${ }^{1,2}$ Stimulants are the most common type of medication prescribed for ADHD and are part of a total treatment program that may include counseling or other therapies. Methylphenidate is the main agent used in children with the disorder. ${ }^{3-5}$ However, the medications used to treat ADHD come with side effects and risks. Restlessness, headache, stomach pain, sleeplessness, and decreased appetite are common adverse reactions with methylphenidate, but are usually controlled by reducing the dose. Currently, children who are treated without the benefit of individualized molecular genotyping have only a $60 \%$ chance of successful long-term treatment. ${ }^{6,7}$

Pharmacogenetics is the study of how an individual's genetic makeup affects the way they respond to drugs. ${ }^{8-10}$ The most commonly studied genes in this respect are the cytochrome P450 (CYP) enzymes, 2D6, 2C19, and 2C9, because they are highly polymorphic. Interestingly, approximately $20 \%-50 \%$ of all medications, including antidepressant and antipsychotic medications, are metabolized by CYP2D6 and CYP2C19. ${ }^{11-15}$ Moreover, CYP2D6 metabolizes many of the psychotropic drugs used
Division of Pharmacogenomics and Personalized Medicine, Department of Pathology, Faculty of Medicine, Ramathibodi Hospital, Mahidol University, Rama 6 Road, Bangkok 10400, Thailand

Tel +6622004331

Fax +66 22004332

Email chonlaphat.suk@mahidol.ac.th
Pharmacogenomics and Personalized Medicine 2013:6 3-7

which permits unrestricted noncommercial use, provided the original work is properly cited. 
for ADHD, including haloperidol, risperidone, aripiprazole, and imipramine. Interindividual variability in the activity of these enzymes can lead to abnormal metabolism of these drugs. ${ }^{16-18}$

Understanding the reduced or increased function of the CYP isoenzymes has helped us to categorize patients into four predicted phenotypes according to allele-related enzyme activity: extensive metabolizers, who have two normal alleles; intermediate metabolizers, who are heterozygous for one deficient allele or have two alleles causing reduced activity; poor or slow metabolizers, who have nonfunctional alleles leading to no enzyme activity and thus an increased risk of adverse effects; and ultrarapid metabolizers, who have more copies of a functional gene, leading to high enzyme activity and thus limited drug efficacy. Therefore, identifying genetic variations in drug-metabolizing enzymes is beneficial for categorizing patients who could experience adverse drug reactions with standard doses of certain drugs. ${ }^{8,9,11,13}$

Pharmacogenetic testing has the potential to identify a more comprehensive, individualized risk profile, allowing personalized therapeutics with doses appropriately adjusted for individual metabolism and advanced screening for predisposition to certain adverse effects. This case report demonstrates the importance of pharmacogenetic testing before embarking on treatment for ADHD in clinical practice.

\section{Case report}

A 6-year-old boy received treatment for ADHD at The Yuwaprasart Waithayopathum Child and Adolescent Psychiatric Hospital, Department of Mental Health Services, Ministry of Public Health, Thailand. Written informed consent was obtained from the patient's legal guardian for publication of this case report and accompanying images. The patient's medical history was obtained from his grandparents, aunt, and his class teacher. The teacher reported that the patient was mischievous, disorderly, ignored people around him, answered questions incorrectly, created and spoke his own language, and did not know how to play with peers. Moreover, he was often absent from class, and was restless and mischievous. He was able to communicate, but only answered questions when directly addressed. However, there was no evidence of congenital disease, convulsion, or brain injury, or any known drug allergies, and there was no family history of psychiatric illness in any close relatives.

According to his mental status examination, the patient was mildly impulsive, mute and not answering the questions, and nodded his head as a response to communication, but made eye contact. The WISC-III (Wechsler Intelligence Scale for Children, 3rd Edition) is used to assess the intelligence quotient (IQ) in these children, and the patient's IQ score was below average at 84 . His nonverbal skills were better than his verbal skills. He was able to screen and analyze patterns, and follow the form of a pattern well. However, he lacked the overall ability to analyze images, his concentration was not sustained, and he would only do what interested him. Most recessive was his social intelligence (especially judgment and common sense) which affected his ability to adapt to daily life.

The psychiatrist diagnosed him as having ADHD with delayed language development, and recommended that most child-rearing problems in this patient would be resolved if he took methylphenidate $5 \mathrm{mg}$ in the morning and at noon. On the first day of treatment, the patient's grandfather gave him methylphenidate $5 \mathrm{mg}$ at $7 \mathrm{am}$, and asked the patient's class teacher to give the boy another dose after lunch. The patient's school teacher reported that he became even more disobedient and mischievous thereafter, did not respond to discipline, had a poor appetite, and became increasingly disruptive. He did not go to sleep until midnight (his usual time of going to sleep being around $8.30 \mathrm{pm}$ ). His grandfather then stopped the methylphenidate, and observed that the boy went to sleep around $8.30 \mathrm{pm}$ as usual.

Thereafter, the patient's behavior returned to almost the same as it was before taking the drug. Two weeks after commencing treatment, his grandfather took him for an IQ test with the clinical psychologist, who advised the grandfather to consult with the pharmacist because he was concerned about the patient being more impulsive after taking methylphenidate. The temporal relationship between methylphenidate and emergence of adverse drug reactions in the patient (insomnia, hyperactivity, and poor appetite) indicated that the methylphenidate dose prescribed had been too high. The pharmacist suggested a new treatment plan to the patient's grandfather, involving rechallenge with half a $10 \mathrm{mg}$ tablet of methylphenidate to be taken once in the morning. After that, the patient became more mischievous, had difficulty sleeping, and would not go to sleep until around 11-12 pm. The patient was then taken to the hospital, where the physician suggested cessation of methylphenidate, instead prescribing half a $0.5 \mathrm{mg}$ tablet of haloperidol and one $10 \mathrm{mg}$ imipramine tablet before bedtime. After taking this prescription on the first night, the patient's behavior was normal. However, on the second night, the patient started to become restless, sleepless, and impulsive, whereupon his grandfather stopped giving him the drugs. He then became better and was more able to communicate. After observing 
the improvement, his grandfather did not give the child any further haloperidol or imipramine.

An adverse reaction to haloperidol was suspected, with restlessness and agitation occurring because of a high drug plasma concentration, so a blood sample was sent to the Laboratory for Pharmacogenomics and Personalized Medicine, Department of Pathology, Somdech Phra Debaratana Medical Center, Faculty of Medicine Ramathibodi Hospital, Mahidol University, for pharmacogenetic testing with the All-InOne Pharmacogenetics for Antipsychotics test (All-In-One PGX; CYP2D6, CYP2C19, and CYP2C9) using microarraybased and real-time polymerase chain reaction techniques. Genotyping for CYP2D6 and CYP2C19 was performed using the AmpliChip ${ }^{\circledR}$ for 29 different alleles of CYP2D6 (including gene duplications and deletions) and two alleles of CYP2C19 (*2, splicing defect G681A single nucleotide polymorphism and *3, stop codon G636A single nucleotide polymorphism) genes. Testing for two single nucleotide polymorphisms for CYP2C9 (*2, C430T, exon 3 and *3, A1075C, exon 7) was also performed. Twenty-nine polymorphisms in CYP2D6 were also tested for: $-1584 \mathrm{C}>\mathrm{G}, 31 \mathrm{G}>\mathrm{A}, 100 \mathrm{C}>\mathrm{T}$, 138 insT, $883 \mathrm{G}>\mathrm{C}, 1023 \mathrm{C}>\mathrm{T}, 1039 \mathrm{C}>\mathrm{T}, 1659 \mathrm{G}>\mathrm{A}$, $1661 \mathrm{G}>\mathrm{C}, 1707 \mathrm{~T}>\mathrm{del}, 1758 \mathrm{G}>\mathrm{T}, 1758 \mathrm{G}>\mathrm{A}$, $1846 \mathrm{G}>\mathrm{A}, 1976 \mathrm{G}>\mathrm{A}, * 20$ cluster, 2539-2542delAACT, 2549 A > del, 2613-2615delAGA, 2850C $>$ T, $2935 \mathrm{~A}>\mathrm{C}$, $3183 \mathrm{G}>\mathrm{A}, 3198 \mathrm{C}>\mathrm{G}, 3277 \mathrm{~T}>\mathrm{C}, 4042 \mathrm{G}>\mathrm{A}, * 36 \mathrm{GC}$, $4180 \mathrm{G}>\mathrm{C}, 1863$ repeats, gene deletion $(* 5)$ and gene duplication. In this study, AmpliChip data analysis software was used to infer the CYP genotype, and to predict the individual's CYP2D6 enzyme activity. The algorithm from the AmpliChip package insert was used for assignment of the predicted phenotypes. There are four phenotypic categories according to allele-related enzyme activity: no enzyme activity alleles (ie, poor metabolizers), $* 3, * 4, * 5, * 6, * 7, * 8$, $* 11, * 14 \mathrm{~A}, * 15, * 19, * 20, * 36, * 40$, and $* 4 \mathrm{XN}$; decreased enzyme activity alleles (ie, intermediate metabolizers), $* 9$, $* 10, * 17, * 29, * 41, * 10 \mathrm{XN}, * 17 \mathrm{XN}$, and $* 41 \mathrm{XN}$; normal enzyme activity alleles (extensive metabolizers), *1, *2, and $* 35$; and increased enzyme activity alleles (ultrarapid metabolizers), $* 1 \mathrm{XN}, * 2 \mathrm{XN}$, and $* 35 \mathrm{XN}$.

Pharmacogenetic testing showed that the child did not have CYP2C9 $(* 1 / * 1)$ or $C Y P 2 C 19(* 1 / * 1)$ gene polymorphisms, a profile compatible with normal enzyme activity, indicating an extensive metabolizer phenotype. However, the patient was found to have a CYP2D $6 * 2 / * 10$ genotype, so was an intermediate metabolizer for this enzyme (see Table 1). This genetic profile may explain the patient's reaction to methylphenidate, haloperidol, and imipramine,
Table I Drug metabolizing genetic profile for this patient as determined by the All-In-One Pharmacogenetics for Antipsychotics test (CYP2D6, CYP2C19, and CYP2C9)

\begin{tabular}{lll}
\hline Drug metabolizing gene & Genotype & Predicted phenotype \\
\hline CYP2D6 & $*_{2} / *_{10}$ & Intermediate metabolizer \\
CYP2C19 & $* 1 / *_{1}$ & Extensive metabolizer \\
CYP2C9 & $*_{1} / *_{1}$ & Extensive metabolizer \\
\hline
\end{tabular}

given that these antipsychotics are metabolized by CYP2D6.

Finally, the patient's psychiatrist suggested reducing the patient's methylphenidate dose from half to one quarter of a tablet $(2.5 \mathrm{mg})$ per day in the morning, and to monitor the clinical response. Haloperidol and imipramine were withdrawn. On the reduced dose of methylphenidate, there was no indication of adverse drug reactions or sleep disorder, and the patient could eat normally. The patient is still taking methylphenidate $2.5 \mathrm{mg} /$ day in the morning. The relatives have been provided with a list of other drugs that are substrates for CYP2D6 and should be avoided in this patient.

\section{Discussion}

Methylphenidate is a psychostimulant commonly used in the treatment of ADHD, and has an established role in the management of this childhood disorder in Thailand. ${ }^{19,20}$ The most common side effects are poor appetite, depression, headache, and stomach ache..$^{3-7}$ There has been a case report of a child with ADHD and a CYP2D6 genotype for ultrarapid metabolism who developed arterial hypertension upon treatment with methylphenidate which resolved when the drug was stopped. ${ }^{21}$

The child in this case report was treated with methylphenidate for ADHD at a dose calculated according to body weight. On this basis, the patient should have tolerated methylphenidate in a dose range of $6.9-13.8 \mathrm{mg}$. However, adverse reactions appeared after taking only a single $5 \mathrm{mg}$ dose, and the patient's quality of life decreased.

Pharmacogenetic testing showed that the patient's CYP2D6 genotype was CYP2D $6 * 2 / * 10$, and thus he was an intermediate metabolizer of methylphenidate. Nervousness and insomnia are the most common adverse reactions reported with methylphenidate. In this case, we found that the patient became more disobedient, mischievous, resistant to discipline, erratic, sleep-deprived, and had a poor appetite.

A previous report showed that CYP2D6 is not involved in the metabolism of methylphenidate. ${ }^{22}$ Drugs that are inhibitors of CYP2D6 when taken concurrently with methylphenidate 
are not involved in the metabolism of methylphenidate and should not affect its plasma concentration. However, methylphenidate possesses some structure similarities to amphetamine which is CYP2D6 substrates. ${ }^{22}$ If CYP2D6 plays a prominent role in the metabolism of methylphenidate, then polymorphisms of the gene may have a significant influence in terms of the response to drug treatment in children with ADHD. Moreover, drug-drug interaction studies indicate that methylphenidate inhibits certain CYP isoenzymes, ${ }^{23}$ but these have not been investigated fully. For example, imipramine is metabolized by different CYP enzymes, but CYP2D6 is always involved. ${ }^{24-26}$

The physician decreased the dosage of methylphenidate to $2.5 \mathrm{mg}$ without re-emergence of the side effects evident at higher doses, with a good therapeutic response. There is increasing evidence to suggest that the CYP2D6 genotype might partially affect the response to methylphenidate and the likelihood of side effects. Therefore, the patient described here should avoid other drugs that are substrates for CYP2D6 (eg, atomoxetine, risperidone) and drugs which inhibit the function of CYP2D6 (eg, fluoxetine), because they will decrease his ability to eliminate methylphenidate. ${ }^{27,28}$

Potential limitations of this case report include its retrospective nature. As the field moves toward personalized treatment of ADHD, well designed pharmacogenetic studies in larger samples are required to determine the utility of pharmacogenetic information in the treatment of this disorder. An important factor when initiating treatment for ADHD is cooperation between the medical team and the patient's caregivers to ensure adherence. Upon being represcribed methylphenidate, the patient's relatives were concerned about continuing adverse reactions. Thus, it was important for the medical team to provide clear and easy-to-understand information to the family, in order that all could work towards the same therapeutic goal, ie, the patient's behavior improving whilst being safe from inappropriate drug use.

\section{Conclusion}

Psychostimulants are essential in the treatment of ADHD. Many studies have clearly acknowledged the efficacy of methylphenidate in reducing the symptoms of ADHD. Until now, the existing evidence recommends taking into account individual variability in response to and side effects of pharmaceuticals for ADHD. ${ }^{7,21,28}$ Therefore, reviewing the results of pharmacogenomic testing prior to prescription provides clinicians with useful individualized data that can be reviewed with the patient and family, to inform them about the role that metabolism may play in the response to treatment, as well as the possibility of adverse drug reactions.

\section{Acknowledgment}

This work was supported by the Khoon Phoom Foundation, Princess Ubolratana Rajakanya Sirivadhana Barnavadi, and Department of Pathology, Mahidol University.

\section{Disclosure}

The authors declare that they have no competing interests in this work.

\section{References}

1. Batra AS, Alexander ME, Silka MJ. Attention-deficit/hyperactivity disorder, stimulant therapy, and the patient with congenital heart disease: evidence and reason. Pediatr Cardiol. 2012;33:394-401.

2. Ferrin M, Vance A. Examination of neurological subtle signs in ADHD as a clinical tool for the diagnosis and their relationship to spatial working memory. J Child Psychol Psychiatry. 2012;53:390-400.

3. McDonagh MS, Peterson K, Thakurta S, Low A. Drug class review: pharmacologic treatments for attention deficit hyperactivity disorder: final update 4 report. Portland, OR: Oregon Health and Science University; 2011. Available from: http://www.ncbi.nlm.nih.gov/books/ NBK84419/. Accessed November 24, 2012.

4. May DE, Kratochvil CJ. Attention-deficit hyperactivity disorder: recent advances in paediatric pharmacotherapy. Drugs. 2010;70:15-40.

5. Findling RL. Evolution of the treatment of attention-deficit/hyperactivity disorder in children: a review. Clin Ther. 2008;30:942-957.

6. Duong S, Chung K, Wigal SB. Metabolic, toxicological, and safety considerations for drugs used to treat ADHD. Expert Opin Drug Metab Toxicol. 2012;8:543-552.

7. Lee J, Grizenko N, Bhat V, Sengupta S, Polotskaia A, Joober R. Relation between therapeutic response and side effects induced by methylphenidate as observed by parents and teachers of children with ADHD. BMC Psychiatry. 2011;11:70.

8. Sadee W. Genomics and personalized medicine. Int J Pharm. 2011;30: $2-4$.

9. Evans WE, Relling MV. Pharmacogenomics: translating functional genomics into rational therapeutics. Science. 1999;286:487-491.

10. Loo TT, Ross CJ, Sistonen J, et al. Pharmacogenomics and active surveillance for serious adverse drug reactions in children. Pharmacogenomics. 2010;11:1269-1285.

11. Zanger UM, Raimundo S, Eichelbaum M. Cytochrome P450 2D6: overview and update on pharmacology, genetics, biochemistry. Naunyn Schmiedebergs Arch Pharmacol. 2004;369:23-37.

12. Brockmöller J, Kirchheiner J, Meisel C, Roots I. Pharmacogenetic diagnostics of cytochrome $\mathrm{P} 450$ polymorphisms in clinical drug development and in drug treatment. Pharmacogenomics. 2000;1:125-151.

13. Ingelman-Sundberg M. Genetic polymorphisms of cytochrome P450 2D6 (CYP2D6): clinical consequences, evolutionary aspects and functional diversity. Pharmacogenomics J. 2005;5:6-13.

14. Kirchheiner J, Rodriguez-Antona C. Cytochrome P450 2D6 genotyping: potential role in improving treatment outcomes in psychiatric disorders. CNS Drugs. 2009;23:181-191.

15. Seeringer A, Kirchheiner J. Pharmacogenetics-guided dose modifications of antidepressants. Clin Lab Med. 2008;28:619-626.

16. Zhou SF. Polymorphism of human cytochrome P450 2D6 and its clinical significance: Part I. Clin Pharmacokinet. 2009;48:689-723.

17. Otani K, Aoshima T. Pharmacogenetics of classical and new antipsychotic drugs. Ther Drug Monit. 2000;22:118-121. 
18. Murray M. Role of CYP pharmacogenetics and drug-drug interactions in the efficacy and safety of atypical and other antipsychotic agents. J Pharm Pharmacol. 2006;58:871-885.

19. Bhudisri S. Attention and disruptive behavior disorder. Psychiatry, Ramathibodi Hospital. Psychiatry, Faculty of Medicine, Ramathibodi Hospital, Mahidol University; 2005. Available from http://www.ramamental.com/medicalstudent/childandteen/attention_deficit_disorder/. Accessed December 15, 2012. Thai.

20. Hongsanguansri S. Attention deficit hyperactivity disorder (ADHD). How to take care patients who have the psychiatry or mental health problems. Physician's guideline. Department of Mental Health. 2001. Available from: http://www.ramamental.com/gp/gp24.PDF. Accessed December 15, 2012. Thai.

21. Bonnet-Brilhault F, Broly F, Blanc R, Furet Y, Barthélémy C, Paintaud G. An ADHD 6-year-old child ultrarapid metabolizer for CYP2D6. J Clin Psychopharmacol. 2006;26:442-444.

22. Wu D, Otton SV, Inaba T, Kalow W, Sellers EM. Interactions of amphetamine analogs with human liver CYP2D6. Biochem Pharmacol. 1997;53:1605-1612.
23. DeVane CL, Markowitz JS, Carson SW, et al. Single-dose pharmacokinetics of methylphenidate in CYP2D6 extensive and poor metabolizers. J Clin Psychopharmacol. 2000;20:347-349.

24. Markowitz JS, Patrick KS. Pharmacokinetic and pharmacodynamic drug interactions in the treatment of attention-deficit hyperactivity disorder. Clin Pharmacokinet. 2001;40:753-772.

25. Hunninghake D. Studies of the inhibition of drug metabolism by methylphenidate [Abstract]. Fed Proc. 1970;29:345.

26. Smith DA, Jones BC. Speculations on the substrate structure-activity relationship (SSAR) of cytochrome P450 enzymes. Biochem Pharmacol. 1992;44:2089-2098.

27. Bertilsson L, Dahl ML, Dalen P, Al-Shurbaji A. Molecular genetics of CYP2D6: clinical relevance with focus on psychotropic drugs. $\mathrm{Br} J$ Clin Pharmacol. 2002;53:111-122.

28. Lam YW, Gaedigk A, Ereshefsky L, Alfaro CL, Simpson J. CYP2D6 inhibition by selective serotonin reuptake inhibitors: analysis of achievable steady-state plasma concentrations and the effect of ultrarapid metabolism at CYP2D6. Pharmacotherapy. 2002;22: 1001-1006.
Pharmacogenomics and Personalized Medicine

\section{Publish your work in this journal}

Pharmacogenomics and Personalized Medicine is an international, peerreviewed, open access journal characterizing the influence of genotype on pharmacology leading to the development of personalized treatment programs and individualized drug selection for improved safety, efficacy and sustainability. This journal is indexed on the American Chemical

\section{Dovepress}

Society's Chemical Abstracts Service (CAS). The manuscript management system is completely online and includes a very quick and fair peer-review system, which is all easy to use. Visit http://www.dovepress. $\mathrm{com} /$ testimonials.php to read real quotes from published authors.

Submit your manuscript here: http://www.dovepress.com/pharmacogenomics-and-personalized-medicine-journal 